\title{
Marketing Innovation and New Product Portfolios. A Compositional Approach
}

\author{
Abdennassar Joueid and Germà Coenders * \\ Department of Economics, University of Girona, Faculty Building of Economics and Management, \\ Campus Montilivi, 17003 Girona, Spain; ajoueid10@gmail.com \\ * Correspondence: germa.coenders@udg.edu; Tel.: +34-972-418736
}

Received: 26 May 2018; Accepted: 15 June 2018; Published: 19 June 2018

\begin{abstract}
Product innovation performance is often measured by means of the percentages in the product portfolio from: (a) innovative products launched for the first time in the market; (b) new products to the firm already extant in the market; and (c) unchanged products. These percentages have often been used to assess the impact of open innovation. More recently, innovation in marketing mix has attracted interest per se, beyond the traditional role of marketing in providing external information about consumer needs. Thus far, portfolio data have been analyzed without considering their constant 100 sum. Apart from violating the usual statistical assumptions, the analysis has interpretational flaws. In this article, we use compositional data analysis methods and show how these shortcomings can be overcome by simple transformations. With Community Innovation Survey data in Spain (2012), we show that marketing innovation is a driver of both sales of new-to-the-firm and new-to-the-market products.
\end{abstract}

Keywords: marketing innovation; open innovation; product portfolio; community innovation survey; compositional data analysis $(\mathrm{CoDa})$

\section{Introduction}

Currently, open innovation is one of the most studied phenomena in the field of research and development [1], although in some respects the idea can be traced back to the classical antiquity [2]. The premise to distinguish open innovation from traditional or closed innovation is intentional use of external knowledge inflows and outflows. In this manner, open innovation can be used as an accelerator of both the process of internal innovation and external market expansion [3]. Knowledge can be introduced into the firm through cooperation and through acquisition from external sources, which include not only universities, research centers and competitors, but also customers (inbound open innovation). Possible information outflows are technology exploitation agreements, the sale of patents or the sheer purposeful revelation of technical secrets (outbound open innovation).

In an open innovation context, innovation performance can be measured in several ways [4]. A commonly used operationalization is the degree of novelty of the product portfolio $[5,6]$. Some examples of suggested novelty grades are new goods or services in the world, products which are new only in the industry, new in the company, new to customers in a given market, products with only incremental innovation, and even products that introduce new trends and changes in market structure and consumption behavior [7]. The Oslo manual [8], which underlies the European Union (EU) official statistics data on innovation, considers the following innovation grades:

- innovated products introduced for the first time in a given market by the firm;

- innovated products which are new to the firm, but were introduced into the market for the first time by other companies (i.e., imitation); and 
- $\quad$ products without significant changes.

At first glance, open innovation appears to be related to a greater ease in imitating innovations carried out elsewhere, while decreasing incentives to innovate. However, many studies show that open innovation activities also have positive effects on the innovation of totally new products in the firms' market or even in the world [4,9], so that, in the so-called open innovation era, companies often have both innovated and imitated products in their portfolio [5].

The role of marketing in innovation has recently started to be redefined [10-14] and adapted to the open innovation paradigm $[15,16]$. Information from and cooperation with customers are key issues in open innovation, and firms can enormously benefit from a closer integration and interplay between the research and development (R\&D) and marketing functions [16]. Marketing innovation can even be open itself, and result from cooperation and external knowledge [17].

Traditionally, the marketing function has been assumed to be to build a relationship between the company and its customers, based on knowledge about their behavior and their reaction to market changes. Then, the R\&D department translates consumer needs and behaviors identified by the marketing department into a basis for new product development [18]. According to a new view on marketing and innovation, firms can also launch products that are not new in themselves, but the result of new marketing strategies, through the introduction of changes and innovations in some of the marketing 4 Ps [10-14]. In that sense, marketing innovation can be defined as the implementation of new marketing methods involving significant changes to a firm's marketing mix: product design or packaging, product placement, product promotion, or product pricing [8]. Marketing then ceases to be a mere tool for market exploration or for commercial exploitation of a new product, and becomes a further impulse towards development and innovation per se [11], especially in service industries $[14,15,19]$. Having said this, the traditional marketing role of information gathering is not opposed to the new role but can reinforce it [13]. Several authors [10,12-14,19-21] studied the determinants of marketing innovation. Regarding the use of marketing innovation as an explanatory variable, investment in marketing innovation of the type just described has been reported to impact sales of innovated products of all innovation grades as a whole [11], product innovation (e.g., frequency of introducing new products) and market performance (e.g., in terms of achieving goals regarding new customers, or market share) [22].

Even if it is often claimed that marketing innovation can provide sustainable competitive advantage $[12,13,20,23]$, the marketing innovation domain is still underresearched [13], and especially so when it comes to its outcomes [11]. To the best of our knowledge, marketing innovation activities have never been empirically tested as predictors of innovated product portfolios. The study of such portfolios is usually made from the percentage of each innovated product category in total sales [5,24]. The analysis of constant-sum data (e.g., percentages adding up to 100) poses considerable statistical challenges, which are often not properly addressed. This article proposes using an approach referred to as compositional data analysis ( $\mathrm{CoDa}$ ), which is the standard method for solving the same problems when treating constant-sum data in chemical, biological and geological analyses. To the best of our knowledge, CoDa has never been applied to product portfolio data or to innovation research.

The purpose of this study was to address the two research gaps identified in the previous paragraph. From a substantive point of view, we analyzed marketing innovation as a determinant of innovation success understood as product portfolio innovativeness. To this end, we related the percentages of innovated products, imitated products and products without changes in the product portfolio to innovation in the 4 Ps, together with some of the inbound open innovation activities considered in the literature. From a methodological point of view, we presented the potential of CoDa for analyzing product portfolio data and illustrated it for a statistically unsophisticated readership. To this end, the article begins with a step-by-step guide to the CoDa statistical methodology, it continues by describing the data used for the analysis, and finally presents the results and their interpretation in the CoDa context. 


\section{Compositional Data Analysis (CoDa)}

Compositional data, that is, data that constitute parts of a whole, cause classical statistical methods to have serious problems that arise mainly but not only from the fact that such data have a constant sum. Compositional data analysis ( $\mathrm{CoDa})$ is the standard statistical analysis method for vectors carrying information about the relative size of their $D$ parts or components [25]. Accordingly, the core interest of researchers lies in the relative importance of said components. Some accessible recent text books on CoDa are [26,27].

Typical CoDa examples in the so-called hard sciences are chemical and geological analyses, in which absolute component amounts only tell about the size of the analyzed chemical or geological sample. Typical CoDa examples in management are market share [28], content analysis in advertising [29], spending distribution [30-32], and financial statement analysis [33]. In these examples, absolute amounts tell about total market size, advertisement length, total expenditure and firm size, respectively. Conversely, CoDa places emphasis on how total size is distributed, as is the case in product portfolio analysis.

Let $\mathbf{z}$ be a vector with $D$ positive components:

$$
\mathbf{z}=\left(z_{1}, z_{2}, \ldots, z_{D}\right), \text { with } z_{j}>0 \text { for all } j=1,2, \ldots, D .
$$

Since size is considered to be irrelevant, the closure of vector $\mathbf{z}$ to a constant $k$ sum is common. For instance, if data are percentages, then $k=100$ and if data are proportions, then $k=1$. This yields the compositional vector $\mathbf{x}$ which resides in a bounded space between 0 and $k$, known as the simplex:

$$
\mathbf{x}=\left(\frac{k z_{1}}{\sum_{j=1}^{D} z_{j}}, \frac{k z_{2}}{\sum_{j=1}^{D} z_{j}}, \ldots, \frac{k z_{D}}{\sum_{j=1}^{D} z_{j}}\right)=\left(x_{1}, x_{2}, \ldots, x_{D}\right) \text { with } x_{j}>0 \text { for all } j=1,2, \ldots, D ; \sum_{j=1}^{D} x_{j}=k .
$$

Regardless of the choice of $k$, or even whether closure is performed at all, the relative information about the $D$ parts should remain the same, which is the so-called compositional equivalence property. Thus, the choice of $k$ does not modify results in any way. The data used in this article imply $k=100$.

Some problems that arise when performing standard statistical analyses on closed compositional data include:

- Compositional data are non-normal.

- One component can increase only if some other decreases. This results in negative spurious correlations and prevents interpreting effects in the usual way of "keeping everything else constant".

- Prediction interval limits of standard statistical models can fall below 0 or above 100.

- The sum of coefficients predicting the different components is zero, and the issue about which components decrease when the component which is modeled increases remains unclear.

From its initial geological origins, CoDa has spawned applications in a wide range of disciplines, notably marketing [28-32,34]. Nowadays, CoDa is not only regarded as a means of solving the statistical assumption problems encountered in compositional data, but as a means of answering research questions concerning relative rather than absolute magnitudes. This is the case in product portfolio analysis in which the relative importance of each type of product is the sole focus of interest, as opposed to total sales.

Aitchison's approach to $\mathrm{CoDa}$ [25] states that all needed information about the relative magnitudes of components lies in the log-ratios among components or among their geometric means, which thus become the standard functional form of transformations in CoDa [25-27,35-37]. In the simplest case of having only $D=2$ components, only one log-ratio is needed:

$$
\log \left(\frac{x_{1}}{x_{2}}\right)=\log \left(\frac{z_{1}}{z_{2}}\right)
$$


There are three main arguments for choosing log-ratios as a functional form in transformations:

- Ratios, geometric means and logarithms constitute natural ways of distilling the information about relative size.

- Log-ratios are unbounded and statistical analyses assuming unbounded variable distributions (e.g., normal) are appropriate.

- Log-ratios are compositionally equivalent, and yield the same result when computed from $\mathbf{x}$ or $\mathbf{z}$, for any closure constant $k$.

$D$-1 non-redundant log-ratios contain all information about the relative importance of $D$ components. Drawing from isometric coordinates [35,36,38], a convenient way of deriving a set of D-1 log-ratios was proposed, called orthogonal coordinates for compositional regression [37]. This method is equivalent to isometric coordinates up to a scaling constant and leads to a more intuitive interpretation of model coefficients [37], which can be tailored to the research questions and hypotheses of interest [35]. Orthogonal coordinates for compositional regression can be built from a sequential binary partition (SBP) of components. To create the first coordinate, the complete composition $\mathbf{x}=\left(x_{1}, x_{2}, \ldots, x_{D}\right)$ is split into two groups of components, for the numerator and the denominator of the coordinate, respectively. In the following step, one of the two groups is further split to create the second coordinate. In any step of the SBP, when the $y$ coordinate is created, a group containing $r+s$ components is split into two: $r$ components $\left(x_{n 1}, x_{n 2}, \ldots, x_{n r}\right)$ are placed in the numerator, and $s$ components $\left(x_{d 1}, x_{d 2}, \ldots, x_{d s}\right)$ in the denominator. The coordinate is a log-ratio of the geometric means of both:

$$
y=\log _{2}\left(\frac{\sqrt[r]{x_{n 1} x_{n 2} \ldots x_{n r}}}{\sqrt[s]{x_{d 1} x_{d 2} \ldots x_{d s}}}\right)
$$

where $\log _{2}$ stands for the logarithm to base 2 . In our article, the product portfolio components are sale share of:

- innovative products launched by the firm for the first time in its market $\left(x_{1}\right)$;

- innovative products launched by the firm but already extant in its market $\left(x_{2}\right)$; and

- unchanged or only marginally modified products $\left(x_{3}\right)$.

Our dependent variables are two orthogonal coordinates for compositional regression created from $x_{1}$ to $x_{3}$ following the procedure outlined above [37]. Interpretable coordinates are easy to compute whenever there is an interpretable SBP of components according to the researchers' questions of interest. In our example, the first partition separates $x_{1}$ from $x_{2}$ and $x_{3}$, and the second partition further separates the group of parts formed by $x_{2}$ and $x_{3}$. This SBP is related to the following research questions concerning a gradation from more to less innovativeness:

- Which innovation activities, including marketing innovation, lead to increasing the share of new-to-the-market products $\left(x_{1}\right)$ while reducing the share of the products with lower degrees of novelty $\left(x_{2}\right.$ and $\left.x_{3}\right)$ ? This is the first coordinate $\left(y_{1}\right)$ corresponding to the first partition. High values of this coordinate are interpreted as a greater weight of market firsts within the sales portfolio of the company:

$$
y_{1}=\log _{2}\left(\frac{x_{1}}{\sqrt{x_{2} x_{3}}}\right) .
$$

- Which innovation activities lead to increasing the share of new-to-the-firm products $\left(x_{2}\right)$ while reducing the share of unchanged products $\left(x_{3}\right)$ ? This corresponds to the second partition, and the second coordinate $\left(y_{2}\right)$. High values of this coordinate are interpreted as a greater weight of sales of new products for the company but already existing in the market, compared to products with few or no changes:

$$
y_{2}=\log _{2}\left(\frac{x_{2}}{x_{3}}\right)
$$


SBPs and coordinates can also be used to express the researchers' hypotheses about trade-offs among components. According to [11,22], marketing innovation is beneficial for product innovation as a whole, without taking the degree of novelty into account. Assuming that marketing innovation is beneficial to the novelty of the product portfolio, we can formulate the following two hypotheses:

Hypothesis 1 (H1). Marketing innovation leads to increasing the share of new-to-the-market products $\left(x_{1}\right)$ while reducing the share of the products with lower degrees of novelty $\left(x_{2}\right.$ and $\left.x_{3}\right)$.

Hypothesis 2 (H2). Marketing innovation leads to increasing the share of new-to-the-firm products $\left(x_{2}\right)$ while reducing the share of unchanged products $\left(x_{3}\right)$.

In addition to using research questions or hypotheses as a basis, coordinates can also be built according to the structure of the data [39], or is it even possible to rerun the analysis with more than one set of coordinates [37]. In any case, the relationship between the chosen set of coordinates (dependent) and the set of predictors can be modeled by means of simultaneous regression models, multivariate analysis of variance models, and multivariate analysis of covariance models, with identical results $[31,40,41]$. After coordinates have been computed, statistical analysis becomes standard in all respects, and researchers can use their favorite software and estimation methods. This includes, for instance, ordinary least squares, outlier-robust methods, and so on. In this article, because of the presence of outliers, we use the robust MM method [42] as implemented in the $r l m$ command in the $\mathrm{R}$ library MASS. Parameter interpretation is as follows. A regression coefficient equal to 1 means that increasing a numerical predictor by one unit or belonging to a category in a qualitative predictor leads to doubling $\left(2^{1}=2\right)$ the ratio between the numerator and denominator geometric averages; a regression coefficient equal to 2 indicates a fourfold increase $\left(2^{2}=4\right)$ in the ratio between the numerator and denominator geometric averages; and so on.

In our article, the product portfolio composition $\left(x_{1}, x_{2}\right.$, and $\left.x_{3}\right)$ as a measure of innovation performance and its explanatory variables are obtained from the Community Innovation Survey (CIS), which is described in the next section.

\section{Data Description}

The CIS is a survey of innovation activity in enterprises carried out by the European Statistical Office (Eurostat). The CIS belongs to the EU science and technology statistics and is carried out biennially in EU member states and several other European Statistical System member countries. The quality of CIS data has benefitted from the learning effect in its multiple editions and from the resources, know-how and quality assurance procedures of both the Eurostat and the national statistical offices of member countries. For this reason, the CIS has been widely used from the early stages of open innovation research onwards [4,9,43-46], including marketing innovation research [10,11,21], and research on sales of innovated products [5,6].

The harmonized survey is designed to provide information on innovativeness across all industries and types of enterprise, including different types of innovation (product, process, organization, and marketing) and various aspects of the development of innovation, such as objectives, sources of information, public funding, innovation expenditure, collaboration, appropriation instruments, etc. We focus our analysis on the eighth CIS edition carried out in Spain in 2012.

The CIS includes questions on the three considered innovated product portfolio components $x_{1}$, $x_{2}$ and $x_{3}$, expressed as percentages of turnover during the survey year (i.e., with $k=100$ ), which are operationalized as follows. Respondents are asked to take into account innovations carried out during the previous three years when defining the innovativeness grades, and to think of both goods and services. To consider a product to be new to the market $\left(x_{1}\right)$, it must: (a) be completely new or at least significantly improved; and (b) have been introduced into the current market by the firm for the first time, although it may have already been available in other markets. To consider a product to be new to 
the firm $\left(x_{2}\right)$, it must fulfil only Condition (a). $x_{3}$ includes turnover from products which do not fulfill either of the above definitions.

If the $x$ variables contain zeros, then coordinates cannot be computed. Zero treatment in CoDa depends on the assumed structure of zeros and the reason for their occurrence. We assume that in the CIS, zeros in the percentage of sales of products with a given degree of innovativeness behave as the so-called absolute zeros, essential zeros or structural zeros in the CoDa literature $[25,47]$. The presence of structural zeros leads to different covariance structures among the variables of interest. In the context of our study, this implies, for instance, that the choice not to introduce any product as market-first $\left(x_{1}=0\right)$, may change the way the firm chooses how to distribute its portfolio between $x_{2}$ and $x_{3}$. As a result, data with different patterns of structural zeros (in our case, with different product types present and absent in their portfolios) have to be considered as separate subpopulations, of which one may be selected for the analysis (or if, alternatively, more than one subpopulation is of interest to the researcher, they must be analyzed separately).

We select the subpopulation of firms with a fully diversified product portfolio regarding innovation, in other words, those with no zeros in $x_{1}, x_{2}$ and $x_{3}(n=1466)$. The group with all three non-zero parts in their product portfolios is the most interesting one, theoretically. A review [48] of research concerning the decision whether to launch a new product to the market for the first time (first mover) or to wait for another firm to be the first and then launch an imitative product (follower) concludes that first mover advantages and follower advantages are contingent on the particular product and may even coexist. This suggests that most firms may be better off by being first movers in some innovated products and late movers in others, so that a fully diversified innovative product portfolio is an interesting object of study per se.

The CIS questionnaire contains a wide range of inbound open innovation activities which can be used as explanatory variables for product portfolios. The CIS admittedly does not cover outbound open innovation, although it is widely acknowledged that inbound open innovation is more prevalent $[49,50]$.

First, open innovation activities in the CIS include cooperation, which is related to active participation in innovation activities with partners [43,51,52]. Cooperation can be considered to be the utmost sign of openness, and has been referred to as coupled open innovation [50,53], which is understood to go one step beyond pure inbound open innovation. The operationalization which follows from the CIS is cooperation on any of the firm's innovation activities with any other enterprise or institution during the three years prior to the survey. Active participation of all parties is required and pure contracting out of work with no active cooperation is explicitly excluded.

Second, they include searching sources of external knowledge [50,54], which leads to tacit knowledge and does not necessarily require formal contracts or monetary resources [5,13]. The CIS asks respondents to rate the importance of information sources to the firm's innovation activities during the three years prior to the survey. In the CIS operationalization, relevant sources are those which provide information for new innovation projects or contribute to the completion of existing projects.

Third, they include acquisition of machinery, knowledge or R\&D, which implies monetary expenses $[44,55]$. Operational definitions in the CIS are as follows and refer to the three years prior to the survey. Acquisition of machinery includes any advanced machinery, equipment, software and buildings as long as they are used for new or significantly improved products or processes. Acquisition of knowledge is defined as acquisition of existing know-how, copyrighted works, patented and non-patented inventions, etc. from other enterprises or organizations for the development of new or significantly improved products and processes. R\&D includes all research and development activities undertaken to create new knowledge or to solve scientific or technical problems, including software development. Acquisition of external R\&D requires a formal contract to other enterprises (which may be enterprises in the same group) or to public or private research organizations.

Fourth, they include marketing innovation $[10,11,21]$. The CIS instructs respondents to consider marketing innovation as the implementation of a new marketing concept or strategy that differs significantly from the firm's existing marketing methods and which has not been used before. Seasonal, 
regular and other routine changes in marketing methods are expressly excluded from the operational definition. As in all other variables, the reference period are the three years prior to the survey. Questions on the following are included: (a) significant changes to the aesthetic design or packaging of a good or service; (b) new media or techniques for product promotion (e.g., the first time use of a new advertising media, a new brand image, and introduction of loyalty cards); (c) new methods for product placement or sales channels (e.g., first time use of franchising or distribution licenses, direct selling, exclusive retailing, and new concepts for product presentation); and (d) new methods of pricing goods or services (e.g., first time use of variable pricing by demand and discount systems). All examples within parentheses are provided in the questionnaire form.

The details on how we code the explanatory variables defined above in this article draw from $[4,9,10,21,45]$ and are explained below:

- Binary variables indicating open innovation activities: (1) cooperation with suppliers of equipment, including also materials, components, or software; (2) cooperation with customers, both public and private; (3) cooperation with competitors, understood in a broad sense as other enterprises in the firms' sector; (4) use of information from consultants and commercial labs; (5) use of information from universities and research institutes, including all higher education institutions and research institutions, governmental, public and private; (6) external R\&D; (7) acquisition of machinery, equipment and software; and (8) acquisition of knowledge.

- Binary variables indicating closed innovation activities: (9) use of information from within the enterprise or enterprise group, and (10) in-house R\&D.

- Binary variable indicating: (11) marketing innovation.

- Control variables: (12) firm size (large enterprise, 250 or more employees; small or medium enterprise (SME), 10 to 249 employees belonging to an enterprise group; and independent $\mathrm{SME}$ ); and (13) industry coded from the NACE classification grouped into nine broad categories (food, mining and construction; textile, fur, wood and paper industries; rubber and plastic manufacturing; metal manufacturing; machinery and equipment manufacturing; other manufacturing industries; retailing, repair and transport; publishing, printing and recorded media industries; and other services).

The activities implying expenses (in-house R\&D, external $R \& D$, acquisition of machinery, equipment and software, and acquisition of knowledge) were already binary in the CIS ( $1=$ Yes, $0=\mathrm{No}$ ). For the information sources, the CIS categories "Not used" and "Low importance" were grouped together and coded as $0=$ No and the categories "Medium importance" and "High importance" were grouped together and coded as $1=$ Yes. For the cooperation variables, the category $1=$ Yes included cooperation with at least one partner of the type given. Marketing innovation was created from the four CIS questions about whether the company had innovated in each of the marketing mix 4 Ps (product design/packaging, placement, promotion and pricing). This binary variable was coded as $1=$ Yes if the firm had innovated in at least one of the 4 Ps.

Table 1 shows the proportion of firms carrying out each of the innovation activities described above, in the overall sample and by firm size. Table 2 shows unchanged products $\left(x_{3}\right)$ to be the prevalent product category (overall geometric average 69.4\%), while the remaining two categories have an approximately equal weight (overall geometric average $15.2 \%$ for $x_{1}$ and $15.4 \%$ for $x_{2}$ ). Overall, independent SMEs have the most innovative portfolio distribution and large enterprises the least.

A simple overview of normality can be provided by standard skewness and kurtosis statistics. As is often the case, coordinates tend to be more normally distributed than raw components. Skewness figures are $1.48\left(x_{1}\right), 1.61\left(x_{2}\right),-0.61\left(x_{3}\right), 0.25\left(y_{1}\right)$, and $0.25\left(y_{2}\right)$. Kurtosis figures are $1.96\left(x_{1}\right), 2.50\left(x_{2}\right),-0.88\left(x_{3}\right), 0.39\left(y_{1}\right)$, and $-0.21\left(y_{2}\right)$.

To check for the presence of multivariate outliers in the coordinate vector, Mahalanobis distances to the coordinate center can be compared to the quantiles of their expected $\chi^{2}$ distribution with $D-1=2$ degrees of freedom in a standard qq-plot (Figure 1). Points to the right of the broken line (drawn at 
the value of the $\chi^{2}$ distribution with 0.999 cumulative probability) can be considered to be outliers. The chisq.plot command in the R library mooutlier was used.

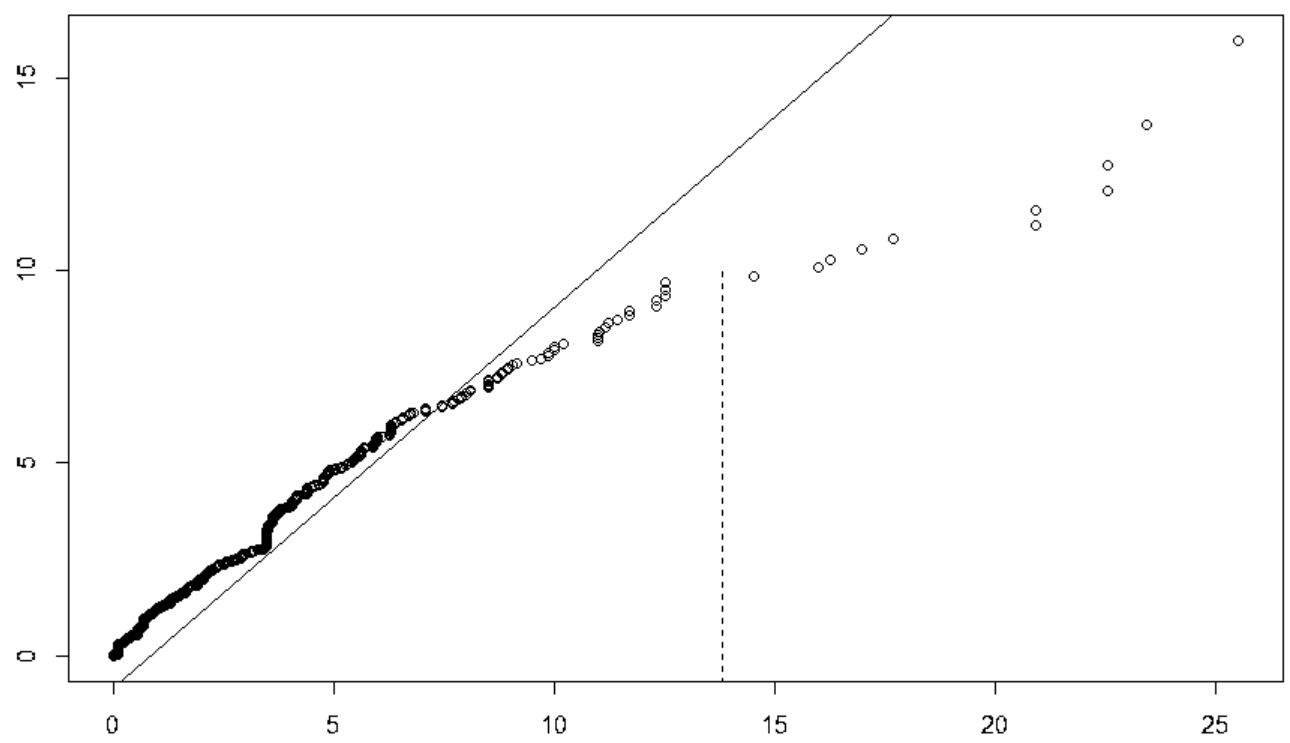

Figure 1. qq plot for assessing the fit of Mahalanobis distances to the $\chi^{2}$ distribution. Solid line shows equality between expected and theoretical quantiles. Broken line is drawn at 0.999 cumulative probability.

Table 1. Proportion of firms engaging in each innovation activity (proportion of Yes answers), by firm size.

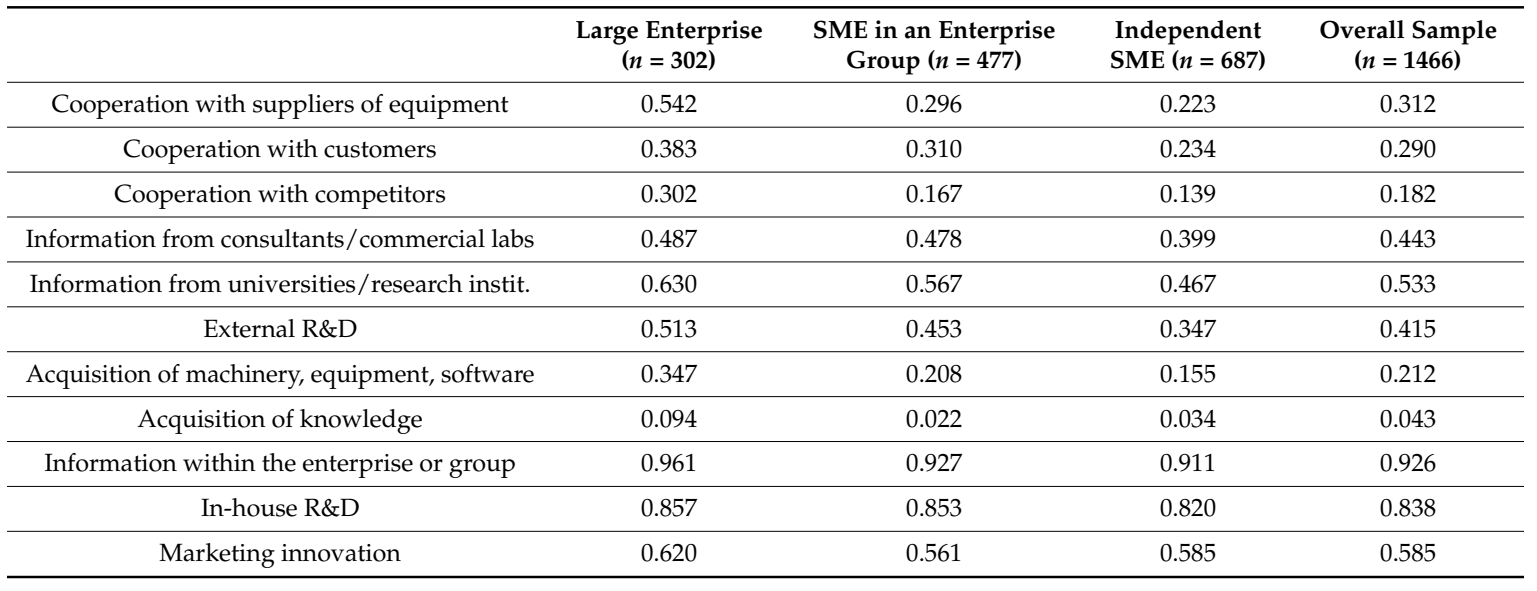

Table 2. Geometric average of product portfolios (percentage), by firm size.

\begin{tabular}{|c|c|c|c|c|}
\hline & $\begin{array}{l}\text { Large Enterprise } \\
\qquad(n=302)\end{array}$ & $\begin{array}{l}\text { SME in an Enterprise } \\
\text { Group }(n=477)\end{array}$ & $\begin{array}{l}\text { Independent } \\
\text { SME }(n=687)\end{array}$ & $\begin{array}{l}\text { Overall Sample } \\
\quad(n=1466)\end{array}$ \\
\hline New to the market $\left(x_{1}\right)$ & 12.1 & 14.0 & 17.8 & 15.2 \\
\hline New to the firm $\left(x_{2}\right)$ & 12.5 & 14.5 & 17.4 & 15.4 \\
\hline Unchanged or marginally modified $\left(x_{3}\right)$ & 75.4 & 71.5 & 64.8 & 69.4 \\
\hline
\end{tabular}

\section{Results and Discussion}

Results in Table 3 show that innovation in the field of marketing is the most influential variable, since it has positive large and significant effects on both coordinates. In other words, both $\mathrm{H} 1$ and $\mathrm{H} 2$ are supported: innovating in at least one of the 4 Ps helps to increase both the percentage of sales of new products in the market while decreasing the other two parts $(\hat{\beta}=0.23, p$-value $=0.009)$, and the percentage of sales of innovated products only within the company while decreasing sales of 
unchanged products $(\hat{\beta}=0.31, p$-value $=0.013)$. This indicates that a company pursuing innovation success, both when it comes to increasing the weight of imitative innovations and new-to-the-market innovations in the product portfolio, will benefit from innovating also in the way of selling them, that is, in product design and packaging, placement, promotion and advertising, or pricing. In numerical terms, when controlling for a range of open innovation activities, marketing innovation multiplies the ratio between sales of innovated products only within the company and sales of unchanged products by $2^{0.31}=1.24$; and the ratio between sales of new products in the market and the geometric mean of sales with lesser degrees of innovativeness by $2^{0.23}=1.17$. To check that statistical significance was maintained under alternative model specifications, we carried out six sensitivity analyses, by removing each group of variables, first one at a time and then all possible combinations of two groups of variables. The considered groups of variables are: (a) the seven variables related to open innovation; (b) the two variables related to closed innovation; and (c) the two control variables -size and industry. Both marketing innovation effects remained positive and statistically significant under all six alternative specifications of the model. $p$-values for the effect on $y_{1}$ were always below 0.007 , and $p$-values for the effect on $y_{2}$ were always below 0.016 .

Table 3. Model estimates, standard errors, $p$-values and coefficients of determination. Controls not shown.

\begin{tabular}{|c|c|c|c|c|c|c|}
\hline & \multicolumn{3}{|c|}{$\begin{array}{l}y_{1} \text { Coordinate New to the Market } \\
\text { over Less or No Novelty }\left(R^{2}=0.069\right)\end{array}$} & \multicolumn{3}{|c|}{$\begin{array}{c}y_{2} \text { Coordinate New to the Firm over } \\
\text { No Novelty }\left(R^{2}=0.065\right)\end{array}$} \\
\hline & $\hat{\beta}$ & s.e. $(\hat{\beta})$ & $p$-Value & $\hat{\beta}$ & s.e. $(\hat{\beta})$ & $p$-Value \\
\hline $\begin{array}{c}\text { Cooperation with suppliers } \\
\text { of equipment }\end{array}$ & 0.17 & 0.11 & 0.131 & 0.33 & 0.16 & 0.039 \\
\hline Cooperation with customers & 0.12 & 0.12 & 0.327 & -0.11 & 0.17 & 0.529 \\
\hline Cooperation with competitors & -0.04 & 0.13 & 0.749 & -0.19 & 0.18 & 0.289 \\
\hline $\begin{array}{c}\text { Information from } \\
\text { consultants/commercial labs }\end{array}$ & -0.01 & 0.09 & 0.897 & 0.03 & 0.13 & 0.818 \\
\hline $\begin{array}{l}\text { Information from } \\
\text { universities/research instit. }\end{array}$ & 0.23 & 0.10 & 0.019 & 0.14 & 0.14 & 0.312 \\
\hline External R\&D & -0.16 & 0.10 & 0.107 & -0.27 & 0.14 & 0.052 \\
\hline $\begin{array}{l}\text { Acquisition of machinery, } \\
\text { equipment, software }\end{array}$ & -0.18 & 0.11 & 0.095 & -0.10 & 0.15 & 0.522 \\
\hline Acquisition of knowledge & 0.35 & 0.22 & 0.110 & 0.55 & 0.31 & 0.077 \\
\hline $\begin{array}{l}\text { Information within the } \\
\text { enterprise or group }\end{array}$ & -0.05 & 0.17 & 0.764 & -0.04 & 0.25 & 0.865 \\
\hline In-house R\&D & 0.19 & 0.13 & 0.153 & 0.35 & 0.19 & 0.060 \\
\hline Marketing innovation & 0.23 & 0.09 & 0.009 & 0.31 & 0.13 & 0.013 \\
\hline
\end{tabular}

Cooperation with suppliers of equipment is significant for the second coordinate $(\hat{\beta}=0.33$, $p$-value $=0.039)$ and includes active collaboration with any provider of equipment, materials, components or software for the purpose of carrying out innovation activities. The positive value of the coefficient indicates that this type of vertical collaboration leads to increasing sales of innovative products at least within the company, while reducing sales of unchanged products. None of the other cooperation variables has a significant effect.

Universities and research institutes $(\hat{\beta}=0.23, p$-value $=0.019)$ constitute the only source of external information that influences sales of innovated products, more specifically by helping to increase the percentage of sales of new products in the firm's market, while reducing the percentage of sales of products that are only new within the company or unchanged. This includes a substantial rating (medium to high) of the importance of information from any kind of public or private higher education or research institution, regarding the firm's innovation activities. 


\section{Conclusions}

The contribution of this article is both applied and methodological. As suggested in the recent applied literature, the marketing function is not only a means to perform market research or to sell the innovative products but can also be a driver of innovation per se. The most important relationship encountered in this article is that between innovation in marketing and product innovation performance, both regarding sales of imitated (H2) and new-to-the-market products $(\mathrm{H} 1)$. Marketing innovation is thus not only related to introducing existing products in the market by another firm, but also to developing products which are new to the firm's market. Marketing innovation is also found to predict innovation performance beyond the predictive power provided by commonly used variables about open innovation activities, and predictive power is maintained under the alternative model specifications considered in the sensitivity analyses. Our results thus agree with the literature on the fact that innovative product design, packaging, pricing, promotion, and distribution strategies can be a promising source of new product performance $[11,22]$. While interpreting the results, it has to be kept in mind that the CIS refers only to marketing concepts and strategies which differ substantially from those previously used by the firm. Routine and seasonal changes in the marketing mix, for instance, are expressly excluded. Examples of substantial marketing innovations would have more to do with radical changes in the physical appearance of the product, first time use of loyalty programs, franchising, relational marketing, community management, yield management, Internet sales, pay-per-view, etc.

Marketing innovation following this definition has been described as a source of sustainable competitive advantage $[12,13,20,23]$. With this objective in mind, firms wishing to enhance marketing innovation may, for instance, invest in organizational learning capabilities [20], innovation training [21], collaboration [19], information and communication technologies [19], and external information absorption [13].

The classical view about the relationship between the marketing and R\&D departments has changed in the so-called open innovation era, and stories of success tell about integration [16], close cooperation, or a high status of marketing within the R\&D department [18]. In the same vein, open information inflows and marketing innovation have been found to be interrelated [13]. Accordingly, open-innovation-oriented crowdsourcing organizations such as INNOCENTIVE (www. innocentive.com) are now often managing challenges with a marketing content.

Regarding the methodological contributions, this article has reviewed the shortcomings of standard analysis of the percentages of sales in the product portfolio, which can lead to errors and inconsistencies. Actually, when reanalyzing the data using $x_{1}$ to $x_{3}$ as dependent variables instead of $y_{1}$ and $y_{2}, 100 \%$ of sample cases had at least one $95 \%$ prediction interval limit above 100 or below 0 . Articles performing such analyses abound using both CIS data [5] and other innovation surveys [24]. This article shows how CoDa can solve most of the shortcomings while providing, among others, an interpretation of the trade-offs between the components according to research questions and hypotheses, and a proper treatment of statistical assumptions. A great advantage of CoDa for applied researchers lies in the fact that once the data have been transformed into coordinates, standard and well understood statistical methods can be applied with any standard statistical software. In this article, we hope to have provided a step-by-step guide for practitioners, which can be used to advantage in product portfolio analysis classified by any product or customer characteristic, not only innovativeness.

A limitation of the study stems from the fact that official statistics data fail to include much of the theoretically relevant information, and is reflected by the fact that only a few significant relationships were found and by the low $\mathrm{R}^{2}$ values. Further research with richer data is needed to extend and confirm the findings. The availability of information about depth and scope of the particular marketing innovations, expenditure in marketing innovation, relationships between the marketing and $R \& D$ departments, etc., would be especially welcome. Along similar lines, product portfolio sales data could make a finer division of innovativeness [7]. Having said this, in our opinion, the lack of explanatory power in this particular example does not detract from the value of the article as a first attempt to 
explain product portfolio share from marketing innovation, and as a methodological illustration. Another issue is the presence of structural zeros, which could be further exploited, for instance, by analyzing subpopulations of firms with fewer than three categories of innovated products in their portfolios. Another issue may be endogeneity, as the relationship between product and marketing innovation has also been conceptualized as going from product to marketing innovation in some of the literature [13]. Finally, a further area of future research is to compare the impact of marketing innovation on innovated product portfolios across countries. To this end, the model used in this article can accommodate moderating effects in the same manner as any other linear model [31].

Author Contributions: Conceptualization, A.J. and G.C.; Data curation, A.J.; Formal analysis, A.J. and G.C.; Funding acquisition, G.C.; Methodology, A.J. and G.C.; Project administration, G.C.; Supervision, G.C.; Writing - original draft, A.J. and G.C.; Writing—review \& editing, G.C.

Funding: The work was supported by the Catalan Autonomous Government (grants 2014 SGR551 and 2017SGR656), by the Spanish Health Ministry (grant CB06/02/1002), by the Spanish Economy and Competitiveness Ministry (grant MTM2015-65016-C2-1-R), and by the University of Girona (grants MPCUdG2016/069 and GDRCompetUdG2017/19). Grant MTM2015-65016-C2-1-R influenced the choice of CoDa methods. The funding sources had no other involvement in the research design, execution and interpretation.

Acknowledgments: Acknowledgements are due to Eurostat for providing us with the 2012 Community Innovation Survey micro-data. Authors are solely responsible for the results obtained. The authors want to thank Anna Arbussà for her comments on the manuscript and Franciane Hochleitner for her assistance in data cleaning.

Conflicts of Interest: The authors declare no conflict of interest.

\title{
Abbreviations
}

\author{
CIS Community Innovation Survey. \\ CoDa Compositional Data Analysis. \\ EU European Union. \\ NACE Nomenclature statistique des Activités économiques dans la Communauté Européenne. \\ R\&D Research and Development. \\ SBP Sequential Binary Partition. \\ SME Small or Medium Enterprise.
}

\section{References}

1. Bogers, M.; Zobel, A.K.; Afuah, A.; Almirall, E.; Brunswicker, S.; Dahlander, L.; Gawer, A.; Gruber, M.; Haefliger, S.; Hagedoorn, J. The open innovation research landscape: Established perspectives and emerging themes across different levels of analysis. Ind. Innov. 2017, 24, 8-40. [CrossRef]

2. Jeon, J.H.; Kim, S.K.; Koh, J.H. Historical review on the patterns of open innovation at the national level: The case of the roman period. J. Open Innov. Technol. Mark. Complex. 2015, 1, 20. [CrossRef]

3. Chesbrough, H. Open Innovation: The New Imperative for Creating and Profiting from Technology; Harvard Business School Press: Boston, MA, USA, 2003.

4. Hochleitner, F.P.; Arbussà, A.; Coenders, G. Inbound open innovation in SMEs: Indicators, non-financial outcomes and entry-timing. Technol. Anal. Strateg. Manag. 2017, 29, 204-218. [CrossRef]

5. Laursen, K.; Salter, A. Open for innovation: The role of openness in explaining innovation performance among U.K. manufacturing firms. Strateg. Manag. J. 2006, 27, 131-150. [CrossRef]

6. Spithoven, A.; Vanhaverbeke, W.; Roijakkers, N. Open innovation practices in SMEs and large enterprises. Small Bus. Econ. 2013, 41, 537-562. [CrossRef]

7. Garcia, R.; Calantone, R. A critical look at technological innovation typology and innovativeness terminology: A literature review. J. Prod. Innov. Manag. 2002, 19, 110-132. [CrossRef]

8. OECD. Oslo Manual, 3rd ed.; Guidelines for Collecting and Interpreting Technological Innovation Data; OECD: Paris, France, 2005.

9. Hochleitner, F.P.; Arbussà, A.; Coenders, G. World-first innovations in an open innovation context. J. Technol. Manag. Innov. 2016, 11, 50-58. [CrossRef]

10. Cesário, M.; Fernandes, S.; Jesus, B.; Monteiro Barata, J. Sources of innovation: The case of Portuguese consultancy sector. J. Technol. Manag. Innov. 2015, 10, 44-52. [CrossRef] 
11. Grimpe, C.; Sofka, W.; Bhargava, M.; Chatterjee, R. R\&D, marketing innovation, and new product performance: A mixed methods study. J. Prod. Innov. Manag. 2017, 34, 360-383. [CrossRef]

12. Medrano, N.; Olarte-Pascual, C. The effects of the crisis on marketing innovation: An application for Spain. J. Bus. Ind. Mark. 2016, 31, 404-417. [CrossRef]

13. Ramirez, F.J.; Parra-Requena, G.; Ruiz-Ortega, M.J.; Garcia-Villaverde, P.M. From external information to marketing innovation: The mediating role of product and organizational innovation. J. Bus. Ind. Mark. 2018. [CrossRef]

14. Zuñiga-Collazos, A.; Castillo-Palacio, M. Impact of image and satisfaction on marketing innovation. J. Technol. Manag. Innov. 2016, 11, 70-75. [CrossRef]

15. Della Corte, V.; Iavazzi, A.; D'Andrea, C. Customer involvement through social media: The cases of some telecommunication firms. J. Open Innov. Technol. Mark. Complex. 2015, 1, 1-10. [CrossRef]

16. Vega-Jurado, J.; Juliao-Esparragoza, D.; Paternina-Arboleda, C.D.; Velez, M.C. Integrating technology, management and marketing innovation through open innovation models. J. Technol. Manag. Innov. 2015, 10, 85-90. [CrossRef]

17. Grzegorz, S.; Robert, S. The use of marketing innovations among SMES. J. Fundam. Appl. Sci. 2018, 10, 257-267. [CrossRef]

18. Drechsler, W.; Natter, M.; Leeflang, P.S. Improving marketing's contribution to new product development. J. Prod. Innov. Manag. 2013, 30, 298-315. [CrossRef]

19. Divisekera, S.; Nguyen, V.K. Determinants of innovation in tourism evidence from Australia. Tour. Manag. 2018, 67, 157-167. [CrossRef]

20. Camisón, C.; Villar-López, A. Non-technical innovation: Organizational memory and learning capabilities as antecedent factors with effects on sustained competitive advantage. Ind. Mark. Manag. 2011, 40, 1294-1304. [CrossRef]

21. Ciliberti, S.; Carraresi, L.; Bröring, S. What drives marketing and organizational innovation in the food industry? A comparison between Italy and Germany. Proc. Syst. Dyn. Innov. Food Netw. 2017, 177-188. [CrossRef]

22. Aksoy, H. How do innovation culture, marketing innovation and product innovation affect the market performance of small and medium-sized enterprises (SMEs)? Technol. Soc. 2017, 51, 133-141. [CrossRef]

23. Ren, L.; Xie, G.; Krabbendam, K. Sustainable competitive advantage and marketing innovation within firms: A pragmatic approach for Chinese firms. Manag. Res. Rev. 2009, 33, 79-89. [CrossRef]

24. Neyens, I.; Faems, D.; Sels, L. The impact of continuous and discontinuous alliance strategies on startup innovation performance. Int. J. Technol. Manag. 2010, 52, 392-410. [CrossRef]

25. Aitchison, J. The Statistical Analysis of Compositional Data. Monographs on Statistics and Applied Probability; Chapman and Hall: London, UK, 1986.

26. Van den Boogaart, K.G.; Tolosana-Delgado, R. Analyzing Compositional Data with R; Springer: Berlin, Germany, 2013.

27. Pawlowsky-Glahn, V.; Egozcue, J.J.; Tolosana-Delgado, R. Modeling and Analysis of Compositional Data; Wiley: Chichester, UK, 2015.

28. Morais, J.; Thomas-Agnan, C.; Simioni, M. Using compositional and Dirichlet models for market share regression. J. Appl. Stat. 2018, 45, 1670-1689. [CrossRef]

29. Marine-Roig, E.; Ferrer-Rosell, B. Measuring the gap between projected and perceived destination images of Catalonia using compositional analysis. Tour. Manag. 2018, 68, 236-249. [CrossRef]

30. Ferrer-Rosell, B.; Coenders, G. Destinations and crisis. Profiling tourists' budget share from 2006 to 2012. J. Destin. Mark. Manag. 2018, 7, 26-35. [CrossRef]

31. Ferrer-Rosell, B.; Coenders, G.; Martínez-Garcia, E. Determinants in tourist expenditure composition- the role of airline types. Tour. Econ. 2015, 21, 9-32. [CrossRef]

32. Ferrer-Rosell, B.; Coenders, G.; Martínez-Garcia, E. Segmentation by tourist expenditure composition. An approach with compositional data analysis and latent classes. Tour. Anal. 2016, 21, 589-602. [CrossRef]

33. Linares-Mustarós, S.; Coenders, G.; Vives-Mestres, M. Financial performance and distress profiles. From classification according to financial ratios to compositional classification. Adv. Account. 2018, 40, 1-10. [CrossRef]

34. Vives-Mestres, M.; Martín-Fernández, J.A.; Kenett, R. Compositional data methods in customer survey analysis. Qual. Reliab. Eng. Int. 2016, 32, 2115-2125. [CrossRef] 
35. Coenders, G.; Martín-Fernández, J.A.; Ferrer-Rosell, B. When relative and absolute information matter. Compositional predictor with a total in generalized linear models. Stat. Model. 2017, 17, 494-512. [CrossRef]

36. Egozcue, J.J.; Pawlowsky-Glahn, V.; Mateu-Figueras, G.; Barceló-Vidal, C. Isometric logratio transformations for compositional data analysis. Math. Geol. 2003, 35, 279-300. [CrossRef]

37. Müller, I.; Hron, K.; Fišerová, E.; Šmahaj, J.; Cakirpaloglu, P.; Vančáková, J. Interpretation of compositional regression with application to time budget analysis. Austrian J. Stat. 2018, 47, 3-19. [CrossRef]

38. Egozcue, J.J.; Pawlowsky-Glahn, V. Groups of parts and their balances in compositional data analysis. Math. Geol. 2005, 37, 795-828. [CrossRef]

39. Martín-Fernández, J.A.; Pawlowsky-Glahn, V.; Egozcue, J.J.; Tolosona-Delgado, R. Advances in principal balances for compositional data. Math. Geosci. 2018, 5, 273-298. [CrossRef]

40. Egozcue, J.J.; Pawlowsky-Glahn, V.; Daunis-i-Estadella, J.; Hron, K.; Filzmoser, P. Simplicial regression. The normal model. J. Appl. Probab. Stat. 2011, 6, 87-108.

41. Martín-Fernández, J.A.; Daunis-i-Estadella, J.; Mateu-Figueras, G. On the interpretation of differences between groups for compositional data. SORT-Stat. Oper. Res. Trans. 2015, 39, 231-252.

42. Yohai, V.; Stahel, W.A.; Zamar, R.H. A procedure for robust estimation and inference in linear regression. In Directions in Robust Statistics and Diagnostics, Part II; Stahel, W.A., Weisberg, S.W., Eds.; Springer: New York, NY, USA, 1991; pp. 365-374.

43. Barge-Gil, A. Cooperation-based innovators and peripheral cooperators: An empirical analysis of their characteristics and behavior. Technovation 2010, 30, 195-206. [CrossRef]

44. Frenz, M.; Ietto-Gillies, G. The impact on innovation performance of different sources of knowledge: Evidence from the UK Community Innovation Survey. Res. Policy 2009, 38, 1125-1135. [CrossRef]

45. Hochleitner, F.; Arbussà, A.; Coenders, G. Evolution of inbound openness profiles in the innovation practices of small and medium-sized enterprises in Spain and Portugal. Int. J. Entrep. Innov. Manag. 2018, in press.

46. Poot, T.; Faems, D.; Vanhaverbeke, W. Toward a dynamic perspective on open innovation: A longitudinal assessment of the adoption of internal and external innovation strategies in the Netherlands. Int. J. Innov. Manag. 2009, 13, 177-200. [CrossRef]

47. Martín-Fernández, J.A.; Palarea-Albaladejo, J.; Olea, R.A. Dealing with zeros. In Compositional Data Analysis. Theory and Applications; Pawlowsky-Glahn, V., Buccianti, A., Eds.; Wiley: New York, NY, USA, 2011; pp. 47-62.

48. Zachary, M.A.; Gianiodis, P.T.; Payne, G.T.; Markman, G.D. Entry-timing enduring lessons and future directions. J. Manag. 2015, 41, 1388-1415. [CrossRef]

49. Huizingh, E.K.R.E. Open innovation: State of the art and future perspectives. Technovation 2011, 31, 2-9. [CrossRef]

50. West, J.; Bogers, M. Leveraging external sources of innovation: A review of research on open innovation. J. Prod. Innov. Manag. 2014, 31, 814-831. [CrossRef]

51. Parida, V.; Westerberg, M.; Frishammar, J. Inbound open innovation activities in high-tech SMEs: The impact on innovation performance. J. Small Bus. Manag. 2012, 50, 283-309. [CrossRef]

52. Rothgang, M.; Cantner, U.; Dehio, J.; Engel, D.; Fertig, M.; Graf, H.; Hinzmann, S.; Linshalm, E.; Ploder, M.; Scholz, A.M.; Töpfer, S. Cluster policy: Insights from the German leading edge cluster competition. J. Open Innov. Technol. Mark. Complex. 2017, 3, 18. [CrossRef]

53. Enkel, E.; Gassmann, O.; Chesbrough, H. Open R\&D and open innovation: Exploring the phenomenon. RED Manag. 2009, 39, 311-316. [CrossRef]

54. Brunswicker, S.; Vanhaverbeke, W. Open innovation in small and medium-sized enterprises (SMEs): External knowledge sourcing strategies and internal organizational facilitators. J. Small Bus. Manag. 2015, 53, 241-1263. [CrossRef]

55. Dubickis, M.; Gaile-Sarkane, E. Transfer of know-how based on learning outcomes for development of open innovation. J. Open Innov. Technol. Mark. Complex. 2017, 3, 4. [CrossRef]

(C) 2018 by the authors. Licensee MDPI, Basel, Switzerland. This article is an open access article distributed under the terms and conditions of the Creative Commons Attribution (CC BY) license (http://creativecommons.org/licenses/by/4.0/). 